\title{
Relationship of Fas ligand expression and atresia during bovine follicle development
}

\author{
D. A. Porter*, R. M. Harman, R. G. Cowan and S. M. Quirk ${ }^{\dagger}$ \\ Department of Animal Science, Cornell University, Ithaca, NY 14853, USA
}

\begin{abstract}
The Fas antigen (Fas) is a cell surface receptor that may be involved in the initiation and progression of follicle cell apoptosis during atresia. Fas initiates apoptosis in sensitive cells after binding Fas ligand (FasL). Other experiments have shown that expression of Fas mRNA and responsiveness to Fas-mediated apoptosis vary in bovine granulosa and theca cells during follicle development. In the present study, FasL mRNA content was measured and Fas and FasL protein expression was examined in bovine granulosa and theca cells of healthy dominant follicles and the two largest atretic subordinate follicles on day 5 of the oestrous cycle (day $\mathbf{0}=$ oestrus), and of dominant follicles from the first wave of follicle development after they had become atretic and showed no growth for 4 days. FasL mRNA content was higher in granulosa cells from atretic compared with healthy follicles. FasL mRNA content was also higher in theca cells
\end{abstract}

from atretic subordinate compared with healthy dominant follicles on day 5, but did not differ between theca cells from healthy and atretic dominant follicles. Immunohistochemical staining for FasL was more intense in theca compared with granulosa cells and in atretic compared with healthy follicles. Immunohistochemical staining for Fas was more intense in granulosa compared with theca cells and in atretic subordinate compared with healthy dominant follicles on day 5. Immune cells, known to express Fas and FasL, were localized in the theca, but not the granulosa, cell layer of all follicles. Higher concentrations of Fas and FasL in cells from atretic follicles, together with the previous demonstration of increased responsiveness of granulosa cells from subordinate follicles to FasL-induced apoptosis, support a potential role for FasL-mediated apoptosis during ovarian follicle atresia.

\section{Introduction}

Most mammalian ovarian follicles that begin to develop never ovulate, but become atretic. Follicle atresia occurs by apoptosis of follicle cells, and follicle cells are thought to initiate apoptosis in the absence of necessary survival signals or in the presence of cytotoxic signals (Hsu and Hsueh, 1997). Fas antigen (Fas) is a cell surface receptor that induces apoptosis when bound by Fas ligand (FasL). Fas may be involved in the initiation and progression of follicle cell apoptosis. Mice injected with agonistic anti-Fas antibody showed an increase in the number of atretic follicles evidenced by an increase in the number of follicles with pyknotic granulosa cells (Sakamaki et al., 1997). In addition, MRL-Ipr/Ipr (lymphoproliferation) mutant mice lack functional Fas and show abnormal ovarian follicle development after 20-24 weeks of age, characterized by an increase in the number of follicles in the secondary stage of development (Sakamaki et al., 1997). Fas and FasL are

*Current address: Dana-Farber Cancer Institute, D740, 44 Binney St, Boston MA 02118, USA

${ }^{+}$Correspondence: 258 Morrison Hall, Cornell University, Ithaca, NY 14853, USA

Email: smq1@cornell.edu expressed in the ovary, and human, mouse, rat and bovine ovarian cells are sensitive to FasL-induced apoptosis under certain conditions in vitro (Quirk et al., 1995, 1997, 1998; Kim et al., 1999; Vickers et al., 2000). Expression of Fas and the existence of a functional Fas pathway in follicle cells indicate a role for Fas in follicle development and atresia.

Cows provide an excellent model in which to study the role of Fas during follicle development and atresia. Bovine follicles develop in waves in which three to six follicles grow larger than $5 \mathrm{~mm}$. One follicle in each wave becomes dominant and continues growing, whereas the subordinate follicles stop growing and become atretic. Cows show two or three waves of follicle growth during each oestrous cycle, but only the dominant follicle present during the follicular phase, in the absence of a functional corpus luteum, ovulates. Dominant follicles present in the luteal phase stop growing and become atretic. Previous studies showed that granulosa and theca cells isolated from all first wave follicles were susceptible to FasL-induced apoptosis to varying degrees. However, expression of Fas mRNA and responsiveness of granulosa cells to FasL-induced apoptosis was higher in atretic subordinate follicles compared with healthy dominant follicles (Porter et al., 2000). In contrast, granulosa cells isolated from preovulatory follicles were susceptible to FasL-induced apoptosis before but not after 
exposure to the LH surge in vivo (Porter and Quirk, 1999). Granulosa cell susceptibility to FasL-induced apoptosis therefore depends on the stage of follicle development.

Expression of FasL within the follicle is probably necessary to induce Fas-mediated apoptosis. Contradictory reports of FasL expression in the ovary indicate that rat granulosa cells do (Kim et al., 1998) or do not (Hakuno et al., 1996) express FasL. However, a number of reports indicate that FasL is expressed in the granulosa cell layer of the ovaries of mice (Guo et al., 1997; Xu et al., 1997), rats (Kim et al., 1998, 1999) and cows (Hu et al., 2001). One study also localized FasL in rat theca cells (Kim et al., 1998). The aim of the present study was to determine whether FasL expression is associated with follicular atresia. FasL mRNA content was measured in granulosa and theca cells, and FasL and Fas protein expression was examined in healthy and atretic bovine follicles isolated during the first wave of follicular development. Since immune cells are known to express FasL, follicles were also stained for CD45, a panleucocyte marker, to determine whether immune cells are a source of Fas or FasL in the follicle.

\section{Materials and Methods}

\section{Materials}

$\mathrm{PGF}_{2 \alpha}$ was obtained from Upjohn Co. (Lutalyse; Kalamozoo, MI). Frozen tissue embedding media (Histo Prep) and microscope slides (Superfrost/Plus) were obtained from Fisher Scientific (Pittsburgh, PA). Monoclonal mouse anti-bovine CD45 antibody (clone CC1) was obtained from Biosource International (Camarillo, CA), mouse anti-human Fas antibody (clone $\mathrm{CH}-11$ ) from Upstate Biotechnology (Lake Placid, NY), polyclonal rabbit anti-rat FasL antibody (IgG, C-178) from Santa Cruz Biotechnology, Inc. (Santa Cruz, CA), Alexa 488-conjugated goat anti-mouse IgG and Alexa 488-conjugated goat anti-rabbit IgG from Molecular Probes (Eugene, OR), Cy2-conjugated goat anti-mouse IgM and rabbit IgG from Jackson ImmunoResearch Laboratories, Inc. (West Grove, PA) and isotype controls (mouse IgG and IgM) from Sigma-Aldrich (St Louis, MO). Avian myeloblastosis virus (AMV) reverse transcriptase (RT) was obtained from Promega (Madison, WI), random hexamer from Pharmacia (Piscataway, NJ) and Taq polymerase from Fisher (Pittsburgh, PA).

\section{Animals}

Ovaries were obtained from cyclic non-lactating Holstein cattle. All procedures were approved by the Cornell University Institutional Animal Care and Use Committee and conducted in accordance with the Guide for the Care and Use of Agricultural Animals in Agricultural Research and Teaching. Animals were injected with a luteolytic dose of $\mathrm{PGF}_{2 \alpha}$ (30 mg per cow followed by $15 \mathrm{mg}$ per cow $12 \mathrm{~h}$ later) between days 7 and 14 of the oestrous cycle (oestrus $=$ day 0 ) and observed for oestrous behaviour twice a day starting 2 days after injection to obtain healthy and atretic follicles during the first wave of follicle development. After the onset of oestrus, animals were examined once a day by transrectal ultrasonography to monitor the onset of the first wave of follicular growth and identify the dominant and two largest subordinate follicles in the wave. Ovaries were removed from two groups of animals by colpotomy (Drost et al., 1992) as follows: from the first group (D5) at day 5 after oestrus when a follicle appeared dominant $(\geqslant 9 \mathrm{~mm}$ ) and the subordinate follicles had shown no growth from day 4 to day 5 , and from the second group (D11) at days 10-12 after oestrus when the dominant follicle in the first wave had not grown for 4 consecutive days.

\section{Tissue preparation}

The dominant and two largest subordinate follicles were dissected from D5 ovaries. Dominant follicles from the first wave of follicular growth were dissected from D11 ovaries. Follicular diameter was measured, and follicular fluid was aspirated using an 18-gauge needle and frozen. All dominant follicles were bisected in Dulbecco's modified Eagle's medium-F12 (DMEM-F12), and a piece of follicle wall $3 \mathrm{~mm} \times 7 \mathrm{~mm}$ was dissected, submerged in embedding media and frozen in liquid nitrogen for immunohistochemistry. Theca interna with attached granulosa cells was separated from the rest of the follicle. The granulosa cells were scraped from the theca interna using a finely drawn Pasteur pipette, collected by centrifugation at $200 \mathrm{~g}$ for $5 \mathrm{~min}$ and frozen in liquid nitrogen for analysis of Fas and FasL mRNA. Theca interna were thoroughly scraped to remove adhering granulosa cells and frozen in liquid nitrogen for mRNA analysis. Subordinate follicles were similarly dissected, but each follicle yielded only enough tissue for either immunohistochemistry or for mRNA analysis. Six subordinate follicles from three animals were assayed for FasL mRNA (values for the two subordinate follicles in each animal were averaged before statistical analysis), and five subordinate follicles from three different animals were used for immunohistochemical staining. Five D5 dominant follicles were obtained from six animals (a dominant follicle was not obtained from one animal that appeared to have codominant follicles) of which two were used to assay FasL mRNA, two were used for immunohistochemistry and one was used for both. Four D11 dominant follicles were isolated of which one was used for assay of FasL mRNA, one was used for immunohistochemistry and two were used for both. Oestradiol concentration in follicular fluid samples was measured by radioimmunoassay as described by Beam and Butler (1997). Follicle diameter and follicular fluid oestradiol concentration were analysed by one-way ANOVA, and comparisons of means were performed by Duncan's new multiple-range test.

\section{Analysis of FasL mRNA}

FasL mRNA was quantified by competitive RT-PCR in granulosa and theca cell fractions ( $n=3$ per type of follicle). 
RNA was reverse transcribed in the presence of increasing concentrations of an internal FasL RNA standard. The FasL RNA standard was prepared by in vitro transcription of a mutated FasL cDNA containing a 50 bp deletion internal to the PCR primer binding sites (corresponding to position 548-597 of human FasL cDNA; Genbank accession no. U11821). Complementary DNA was amplified by PCR in the presence of $\left.{ }^{32} \mathrm{P}\right] \mathrm{dCTP}$. PCR primers for FasL were designed to span the position of two introns and to generate a 294 bp fragment for the sample RNA and a 244 bp fragment for the internal RNA standard (positions of $5^{\prime}$ and 3' bovine primers correspond to positions 426-450 and 702-719 of human FasL, respectively). PCR products were separated on an agarose gel, and the radioactive intensity of sample and standard bands was determined by phosphorimaging. Sample FasL mRNA concentration was calculated from the linear regression of standard concentration versus the ratio of sample intensity:standard intensity (Vickers et al., 2000). On the basis of an RNA pool tested in each assay, the interassay coefficient of variation was $7.4 \%$ ( $n=6$ assays). Data were analysed by one-way ANOVA followed by Duncan's new multiple-range test.

\section{Immunohistochemistry}

Sections $(10 \mu \mathrm{m})$ of frozen follicle wall ( $n=3$ per type of follicle) were cut at $-20^{\circ} \mathrm{C}$ and mounted onto microscope slides. Slides were air-dried for $30 \mathrm{~min}$ at room temperature, and sections were fixed in cold acetone for $2 \mathrm{~min}$, rehydrated for $3 \times 5 \mathrm{~min}$ in $0.01 \mathrm{~mol} \mathrm{PBS} \mathrm{I}^{-1}$, blocked with $1 \%$ normal goat serum (for anti-FasL and anti-CD45 antibodies) or normal donkey serum (for anti-Fas antibody) and stained for FasL, Fas or CD45 proteins. Sections were incubated for $2 \mathrm{~h}$ at room temperature with $2 \mu \mathrm{g}$ rabbit antirat FasL antibody $\mathrm{ml}^{-1}$ (C-178), $10 \mu \mathrm{g}$ mouse anti-human Fas antibody $\mathrm{ml}^{-1}$ (clone $\mathrm{CH}-11$ ) or $5.0 \mu \mathrm{g}$ mouse antibovine CD45 antibody $\mathrm{ml}^{-1}$ (clone CC1). C-178 and $\mathrm{CH}-11$ antibodies detect bovine FasL and Fas, respectively, by immunohistochemistry (Hu et al., 2001). CD45 is a cell surface antigen that is present on all leucocytes and their progenitors (Bembridge et al., 1993). Control sections were similarly incubated with $2 \mu \mathrm{g}$ rabbit $\lg \mathrm{G} \mathrm{ml}^{-1}, 10 \mu \mathrm{g}$ mouse IgM ml-1, or $5.0 \mu \mathrm{g}$ mouse IgG isotype control antibodies $\mathrm{ml}^{-1}$. Sections were rinsed $(3 \times 5 \mathrm{~min})$ in PBS and incubated with $0.5 \mu \mathrm{g}$ Alexa 488-conjugated goat antirabbit IgG $\mathrm{ml}^{-1}, 0.125 \mu \mathrm{g}$ Cy2-conjugated donkey antimouse IgM ml-1, or $2 \mu \mathrm{g}$ Alexa 488-conjugated goat anti-mouse $\operatorname{lgG} \mathrm{ml}^{-1}$. All antibodies were diluted in PBS containing $2 \%$ BSA. Sections were observed under phasecontrast and epifluorescent illumination using a $495 \mathrm{~nm}$ excitation filter and a $520 \mathrm{~nm}$ absorption filter.

\section{Results}

\section{Follicular characteristics}

On day 5 after oestrus, one follicle had become dominant and was larger than the second largest follicle of
Table 1. Characteristics of bovine follicles

\begin{tabular}{lrcc}
\hline Follicle & $n$ & $\begin{array}{c}\text { Follicular } \\
\text { diameter } \\
(\mathrm{mm})\end{array}$ & $\begin{array}{c}\text { Follicular fluid } \\
\text { oestradiol } \\
\left(\mathrm{ng} \mathrm{ml}^{-1}\right)\end{array}$ \\
\hline Day 5 & & & \\
$\quad$ Dominant & 5 & $13.7 \pm 0.7$ & $531.0 \pm 69.7$ \\
$\quad$ Subordinate & 11 & $7.7 \pm 0.3^{*}$ & $17.2 \pm 14.6^{*}$ \\
Day 11 & 4 & $15.3 \pm 1.3$ & $8.7 \pm 2.0^{*}$ \\
\hline
\end{tabular}

*Within columns $P<0.05$ versus day 5 dominant follicle.

the same wave by at least $4 \mathrm{~mm}$ in five of six animals (Table 1). In one animal, the second largest follicle was probably co-dominant because it was only $1.5 \mathrm{~mm}$ smaller than the largest follicle and had a high oestradiol concentration in the follicular fluid. In this animal, the next largest $(5 \mathrm{~mm})$ subordinate follicle of the same wave was used for immunohistochemical staining. All subordinate follicles analysed had shown no growth between day 4 and day 5 after oestrus. Dominant follicles stopped growing $6-8$ days after oestrus. These follicles were isolated after 4 days of no growth, on day $10(n=1), 11(n=1)$ or $12(n=2)$ of the oestrous cycle and are referred to as D11 follicles. Follicular fluid oestradiol concentration confirmed whether follicles isolated at different stages of development were healthy or atretic. Follicular fluid from D5 dominant follicles had high concentrations of oestradiol, whereas follicular fluid from D5 subordinate and D11 dominant follicles had low concentrations of oestradiol (Table 1).

\section{Expression of FasL $m R N A$}

FasL mRNA was detected by competitive RT-PCR in granulosa and theca cell fractions from all follicles. Granulosa cell FasL mRNA content (amol $\mu \mathrm{g}^{-1} \mathrm{RNA}$ ) was 3.5-fold higher in D5 subordinate and 2.8-fold higher in D11 atretic follicles versus healthy D5 dominant follicles (Fig. $1 ; P<0.05$ ). FasL mRNA was also 2.3 -fold higher in theca from D5 atretic subordinate versus healthy D5 dominant follicles $(P<0.05)$, but did not differ between theca from healthy D5 versus atretic D11 dominant follicles (Fig. 1). FasL mRNA content was higher in theca compared with granulosa cells from all follicles.

\section{Immunohistochemistry}

FasL. Granulosa and theca cells from all follicles stained positively for FasL (Fig. 2). Staining for FasL was more intense in theca compared with granulosa cells, consistent with differences in mRNA content. Staining for FasL was more intense in granulosa cells from atretic subordinate follicles compared with healthy dominant follicles on day 5 . Staining for FasL was more intense in theca from atretic D5 subordinate and D11 follicles compared with healthy D5 dominant follicles. 


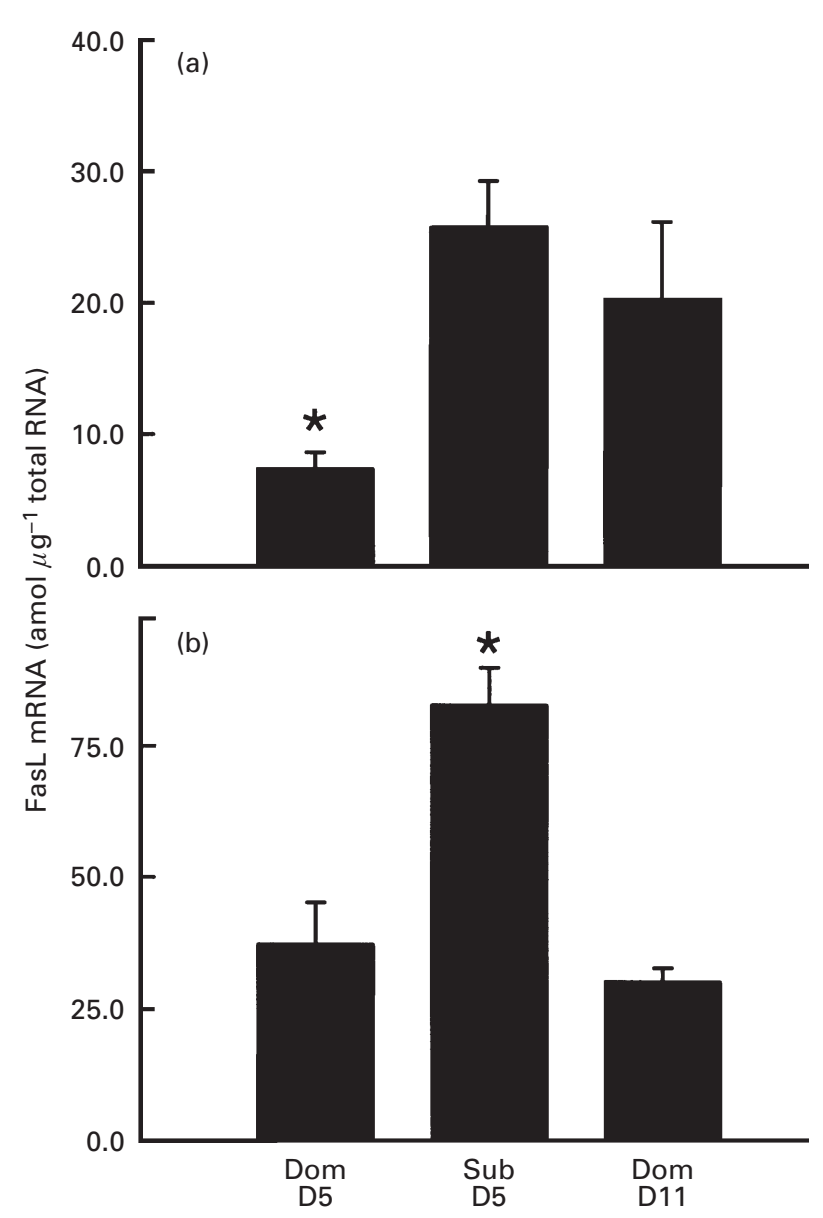

Fig. 1. Fas ligand (FasL) mRNA in bovine (a) granulosa cells and (b) theca cells isolated from dominant (Dom) and subordinate (Sub) follicles on day 5 (D5) and Dom follicles on days 10-12 (D11) of the oestrous cycle. Data are mean $\pm \operatorname{SEM}(n=3) .{ }^{*} P<0.05$ versus other follicles.

Fas. Granulosa and theca cells from all follicles stained positively for Fas (Fig. 2). Staining for Fas was more intense in granulosa cells compared with theca. Staining for Fas was more intense in granulosa and theca cells from atretic subordinate compared with healthy dominant follicles on day 5. Staining for Fas also appeared intense in granulosa and theca of atretic D11 follicles.

CD45. CD45-positive immune cells were localized in the theca but not granulosa cell layers of all follicles (Fig. 2).

\section{Discussion}

Expression of FasL mRNA is high in atretic subordinate compared with healthy dominant follicles isolated during the first wave of follicle development during the bovine oestrous cycle. Qualitative assessment of FasL protein by immunocytochemistry indicates that FasL protein changes in a similar manner. In previous studies, Fas mRNA and responsiveness of granulosa cells to FasL-induced apoptosis were higher in atretic subordinate follicles relative to healthy dominant follicles on day 5 of the oestrous cycle (Porter et al., 2000). The current study shows that staining for Fas protein is also high in atretic follicles. The fact that both mRNA and protein for Fas and its ligand are high in follicles undergoing atresia provides support for the possibility that the Fas pathway is involved in the initiation and progression of atresia. Studies using rats have shown higher expression of Fas and FasL in granulosa cells from atretic compared with healthy follicles, but did not show differences in FasL expression in the theca (Kim et al., 1998, 1999). In bovine follicles, expression of FasL in both theca and granulosa cells increased during atresia.

The challenge of determining how the Fas pathway may be triggered during atresia is difficult to address in vivo but has been studied in bovine granulosa cells in vitro. Growth factors thought to promote follicle cell survival, such as insulin-like growth factor (IGF), basic fibroblast growth factor (bFGF) and epidermal growth factor (EGF) (Hsu and Hsueh, 1997), inhibit FasL-induced apoptosis of bovine granulosa cells, and addition of serum to culture media also prevents FasL-induced apoptosis (Quirk et al., 2000). Removal of serum from media induced apoptosis of bovine granulosa cells (Hu et al., 2001). Cell death after serum withdrawal was associated with increased expression of both Fas and FasL proteins. Furthermore, cell death was inhibited by reagents that prevented binding of FasL to Fas, providing evidence that apoptosis was mediated at least partially by binding of endogenous Fas and FasL on granulosa cells (Hu et al., 2001). The results of studies in vitro, together with the findings presented in the current study, indicate that expression of both Fas and FasL on granulosa cells in follicles that lack the appropriate growth factors is likely to promote follicular atresia. Several proteins that inhibit apoptosis have been identified in ovarian and other types of cell (Sato et al., 1995; Liston et al., 1996; Irmler et al., 1997; Li et al., 1998; Quirk et al., 1998), and expression of the inhibitor of apoptosis proteins (IAPs), Xiap and Hiap-2, is suppressed in cells of atretic rat follicles (Li et al., 1998). Therefore, the activity of the Fas pathway is likely to be regulated by growth and survival factors and by intracellular modulators of apoptosis.

Staining for FasL protein was more intense in theca compared with granulosa cells in all follicles, consistent with a higher content of FasL mRNA. Staining for FasL was observed throughout the theca layer, indicating that most or all theca cells express FasL. Immune cells are known to express Fas and FasL (Nagata, 1997; Hirano et al., 1998) and have been localized in ovarian follicles (Best et al., 1996). In the present study, follicles were stained for CD45, a pan-leucocyte marker, to investigate whether immune cells were a significant source of Fas or FasL in these experiments. In all follicles, CD45-positive immune cells were detected in a limited number of discrete cells present 

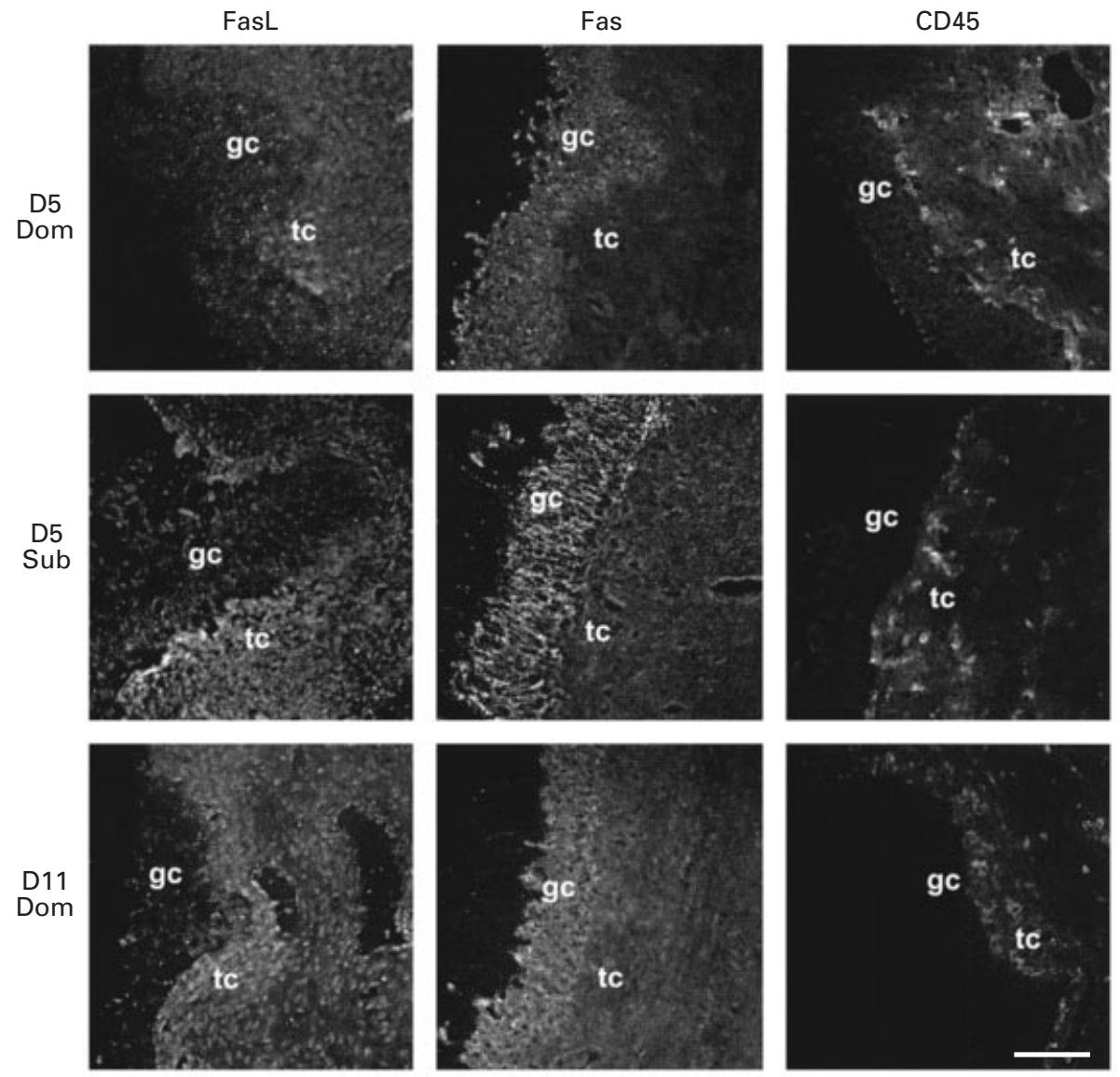

Isotype controls
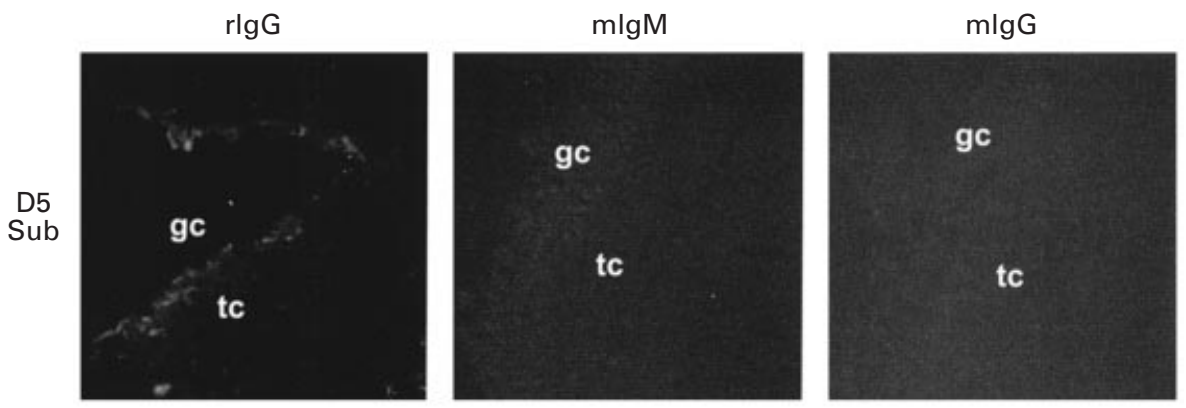

Fig. 2. Immunohistochemistry of Fas ligand (FasL), Fas and CD45 expression in bovine follicle wall isolated from dominant (Dom) and subordinate (Sub) follicles on day 5 (D5) and Dom follicles on days 10-12 (D11) of the oestrous cycle. In each panel, the granulosa cell (gc) layer appears on the left and is separated from the theca cell (tc) layer by a basement membrane. Isotype controls for FasL (rabbit IgG, rlgG), Fas (mouse IgM, mlgM), and CD45 (mouse IgG, $\mathrm{mlgG}$ ) are shown for sections of follicle wall from subordinate follicles on day 5 (D5 Sub). Scale bar represents $100 \mu \mathrm{m}$.

within the theca layer and its vasculature, but not in the granulosa cell layer. Therefore, immune cells were not a source of Fas or FasL in the granulosa cell layer, but they may contribute to the observed expression in theca. It is possible, although not tested in the current study, that immune cells present in the follicle wall release functional, soluble FasL that may have local effects.

Staining for Fas protein was more intense in granulosa compared with theca cells, consistent with the report that theca expression of Fas mRNA was only $5 \%$ of that 
observed in the granulosa cell layer (Porter et al., 2000). Despite lower expression of Fas in theca, other studies showed that the percentage of theca cells susceptible to FasL-induced apoptosis in vitro was similar to the range observed for granulosa cells (Porter et al., 2000). Unlike granulosa cells, the degree of theca cell responsiveness to FasL-induced apoptosis did not differ between first wave healthy and atretic follicles (Porter et al., 2000). These results indicate that the Fas pathway is regulated differently in granulosa and theca cells and by mechanisms other than, or in addition to, regulation of Fas expression.

In conclusion, these results indicate differences in expression of Fas and FasL by follicle cells at various stages of development and are consistent with a potential role for the Fas pathway in ovarian follicular atresia.

This work was supported by grants from the USDA (98-352036220) and NIH (HD 32535). The authors thank W. R. Butler and S. Pelton for performing oestradiol radioimmunoassays.

\section{References}

Beam SW and Butler WR (1997) Energy balance and ovarian follicle development prior to the first ovulation post partum in dairy cows receiving three levels of dietary fat Biology of Reproduction 56 133-142

Bembridge GP, Howard CJ, Parsons KR and Sopp P (1993) Identification of monoclonal antibodies specific for bovine leukocyte common antigen (CD45) together with a novel broadly expressed leukocyte differentiation antigen, BoWC11 Veterinary Immunology and Immunopathology 39 115-120

Best CL, Pudney J, Welch WR, Burger N and Hill JA (1996) Localization and characterization of white blood cell populations within the human ovary throughout the menstrual cycle and menopause Human Reproduction 11 790-797

Drost M, Savio JD, Barros CM, Badinga L and Thatcher WW (1992) Ovariectomy by colpotomy in cows Journal of the American Veterinary Medical Society $200337-339$

Guo MW, Xu JP, Mori E, Sato E, Saito S and Mori T (1997) Expression of Fas ligand in murine ovary American Journal of Reproductive Immunology 37 391-398

Hakuno N, Koji T, Yano T, Kobayashi N, Tsutsumi O, Taketani Y and Nakane PK (1996) Fas/APO-1/CD95 system as a mediator of granulosa cell apoptosis in ovarian follicle atresia Endocrinology 137 1938-1948

Hirano A, Brown WC, Trigona W, Tuo W and Estes DM (1998) Kinetics of expression and subset distribution of the TNF superfamily members CD40 ligand and Fas ligand on T lymphocytes in cattle Veterinary Immunology and Immunopathology 61 251-263

Hsu SY and Hsueh AJW (1997) Hormonal regulation of apoptosis. An ovarian perspective Trends in Endocrinology and Metabolism 8 207-213

Hu C-L, Cowan RG, Harman RM, Porter DA and Quirk SM (2001)
Apoptosis of bovine granulosa cells after serum withdrawal is mediated by Fas antigen (CD95) and Fas ligand Biology of Reproduction 64 518-526

Irmler M, Thome M, Hahne M et al. (1997) Inhibition of death receptor signals by cellular FLIP Nature 388 190-195

Kim J-M, Boone DL, Auyeung A and Tsang BK (1998) Granulosa cell apoptosis induced at the penultimate stage of follicular development is associated with increased levels of Fas and Fas ligand in the rat ovary Biology of Reproduction 58 1170-1176

Kim J-M, Yoon Y-D and Tsang BK (1999) Involvemment of the Fas/Fas ligand system in p53-mediated granulosa cell apoptosis during follicular development and atresia Endocrinology 140 2307-2317

Li J, Kim J-M, Liston P, Li M, Miyazaki T, Makenzie AE, Korneluk RG and Tsang BK (1998) Expression of inhibitor of apoptosis proteins (IAPs) in rat granulosa cells during ovarian follicular development and atresia Endocrinology 139 1321-1328

Liston P, Roy N, Tamai K et al. (1996) Suppression of apoptosis in mammalian cells by NAIP and a related family of IAP genes Nature $\mathbf{3 7 9}$ 349-353

Nagata S (1997) Apoptosis by death factor Cell 88 355-365

Porter DA and Quirk SM (1999) Susceptibility of bovine granulosa cells to Fas antigen-mediated apoptosis differs in cells isolated before or after the LH surge Biology of Reproduction $\mathbf{6 0}$ Supplement 1148

Porter DA, Vickers SL, Cowan RG, Huber SC and Quirk SM (2000) Expression and function of Fas antigen vary in bovine granulosa and theca cells during ovarian follicular development and atresia Biology of Reproduction 62 62-66

Quirk SM, Cowan RG, Joshi SG and Henrikson KP (1995) Fas antigenmediated apoptosis in human granulosa/luteal cells Biology of Reproduction 52 279-287

Quirk SM, Cowan RG and Huber SH (1997) Fas antigen-mediated apoptosis of ovarian surface epithelial cells Endocrinology $1384558-4566$

Quirk SM, Porter DA, Huber SC and Cowan RG (1998) Potentiation of Fas-mediated killing of murine granulosa cells by interferon- $\gamma$, tumor necrosis factor $\alpha$ and cycloheximide Endocrinology 139 4860-4869

Quirk SM, Harman RM and Cowan RG (2000) Regulation of Fas antigen (Fas, CD95)-mediated apoptosis of bovine granulosa cells by serum and growth factors Biology of Reproduction 63 1278-1284

Sakamaki K, Yoshida H, Nishimura Y, Nishikawa S-I, Manabe N and Yonehara Y (1997) Involvement of Fas antigen in ovarian follicular atresia and luteolysis Molecular Reproduction and Development 47 11-18

Sato T, Irie S, Kitada S and Reed JC (1995) FAP-1: a protein tyrosine phosphatase that associates with Fas Science 268 411-415

Vickers SL, Cowan RG, Harman RM, Porter DA and Quirk SM (2000) Expression and activity of the Fas antigen in bovine ovarian follicle cells Biology of Reproduction 62 54-61

Xu JP, Li X, Mori E, Sato E, Saito S, Guo MW and Mori T (1997) Expression of Fas-Fas ligand system associated with atresia in murine ovary Zygote $5321-327$

Received 18 August 2000.

First decision 30 October 2000.

Accepted 5 December 2000. 